\title{
Effect of Operator Experience on Outcome of Radiofrequency Catheter Ablation of Accessory Pathways
}

\author{
Hugh Calkins, MD, Rafel El-Atassi, MD, Steven J. Kalbfleisch, MD, Jonathan J. Langberg, MD, \\ and Fred Morady, MD
}

$\mathbf{R}$ adiofrequency catheter ablation of accessory pathways has been shown to be safe and effective, and is rapidly becoming the treatment of choice for paticnts with the Wolff-Parkinson-White syndrome or paroxysmal supraventricular tachycardia involving a concealed accessory pathway. ${ }^{1-6}$ Because radiofrequency catheter ablation requires skill in mapping and catheter manipulation, the outcome is at least in part operator-dependent. The purpose of this study was to determine the effect of operator experience on the outcome of radiofrequency catheter ablation of accessory pathways by analyzing the changes in efficacy and duration of the procedure as experience increased.

The subjects of this study were the first 400 patients (164 female and 236 male; mean age $35 \pm 18$ years, range 13 to 82 ) to undergo radiofrequency catheter ablation of an accessory pathway at the University of Michigan Medical Center between February 1990 and May 1992. No structural heart disease was present in 388 patients, 4 had coronary artery disease, 4 had Ebstein's anomaly, and 4 had other types of heart disease. In each patient, a diagnostic electrophysiology test was performed in conjunction with catheter ablation. The abbreviated approach used for radiofrequency catheter ablation of accessory pathways at this institution was previously described., ${ }^{2,5}$ Left free wall accessory pathways were approached from the ventricular aspect of the mitral annulus, and right free wall and septal accessory pathways were approached through the inferior vena cava. Catheter ablation procedures were performed by a team of 3 attending physicians and 8 electrophysiology fellows; the 3 physicians were continuously involved in the ablation program, whereas the 8 fellows participated in catheter ablation procedures for 6 to 18 months each. Catheter manipulation was performed primarily by the electrophysiology fellows. Mapping of accessory pathways, and identification of appropriate target sites for radiofrequency energy delivery were based on electrogram analysis performed by $I$ attending physician. The equipment used for radiofrequency catheter ablation procedures remained constant in all 400 patients. The catheters used for mapping and radiofrequency energy delivery all had a deflectable curve and $4 \mathrm{~mm}$ distal tip. In each patient, the duration of the ablation procedure (including the time needed for inserting and positioning catheters), the

From the University of Michigan Medical Center, Division of Cardiology, B1 F245, 1500 E. Medical Center Drive, Ann Arbor, Michigan 48109-0022. Dr. Calkins' current address is: Division of Cardiology, Johns Hopkins Hospital, $600 \mathrm{~N}$. Wolfe Street, Baltimore, Maryland 21287. Manuscript received May 21, 1992; revised manuscript received and accepted September 22, 1992. diagnostic electrophysiology test and the catheter ablation procedure was recorded. The duration of the procedures generally was limited to 4 hours.

The effect of operator experience on the outcome of catheter ablation was examined by comparing the efficacy of the initial attempt at catheter ablation in 8 consecutive groups of 50 patients each. Comparison of the efficacy of catheter ablation in consecutive groups of patients was performed using a contingency table analysis. The effect of operator experience was also examined by comparing the duration of successful ablation procedures and the number of applications of radiofrequency energy needed for success in consecutive groups of 50 patients each. Comparisons of procedure duration were performed by analysis of variance. A $p$ value $<0.05$ was considered significant.

Four hundred nineteen accessory pathways were identified in 400 patients; 249 pathways were located in the free wall of the left ventricle, 72 were posteroseptal, 74 were located in the free wall of the right ventricle, 17 were anteroseptal, and 7 were midseptal. Two hundred eighty-one accessory pathways were manifest and 138 were concealed. Radiofrequency catheter ablation was successful in eliminating conduction in all accessory pathways in 381 patients (95\%). The percentage of patients in whom the first attempt at catheter

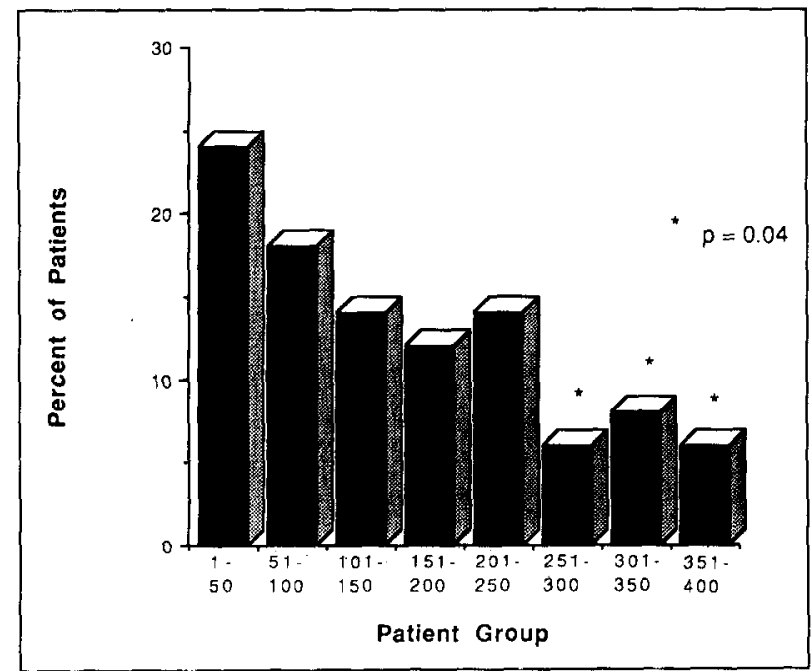

FIGURE 1. Percentage of patients with unsuccesoful initial attempt at catheter ablation of an accescory atrioventricular connection. Horizontel axis, consecutive groups of par ients who underwent attempt at radiofrequency catheter ablation (8 groups of 50 patients each). Vertical axls, percentade of patients with unsuccessful initid attempt at catheter ablation in each group. Percentage of patients with unsuccessful initial attempt at catheter dblation decreased significantly only after experience in 250 patients ( $p=$ $0.04)$. 


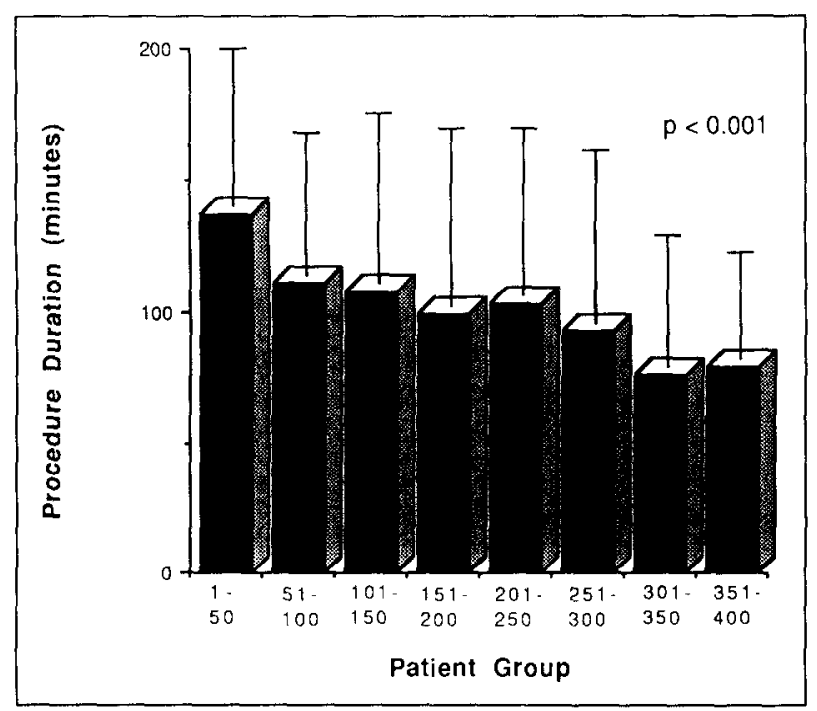

FIGURE 2. Duration of successful attempts at catheter abla tion. Horkontal axis, consecutive groups of patients who underwent attempt at radiofrequency catheter ablation (8 groups of 50 patients each). Vertical axis, mean duration of successful radiofrequency cathoter ablation sessions in each group. With increasing experience, mean procedure duration decreased progressively (p <0.001).

ablation was unsuccessful decreased slowly over time from $24 \%$ in the first 50 patients to $4 \%$ in the eighth and most recent group of 50 patients $(p<0.05)$. Although this improvement in the efficacy of the initial catheter ablation session was achieved in a continuous fashion, a statistically significant decrease in the percentage of patients with an unsuccessful initial catheter ablation session was observed only after 250 ablation procedures were performed (Figure I; $p<0.05$ ). The duration of successful ablation sessions decreased progressively as experience increased, from $138 \pm 59 \mathrm{~min}$ utes in the first 50 patients to $79 \pm 41$ minutes in the eighth group of 50 patients (Figure $2 ; p<0.001$ ). The mean number of applications of radiofrequency energy delivered during successful ablation sessions in the first group of patients $(8 \pm 6$, median 6 , range 1 to 23$)$ was no different than in any other group, including the most recent one $(9 \pm 8$, median 6 , range 1 to $25 ; p=0.7)$.

The same type of catheter was used for mapping and ablation in all patients in this study, and therefore, the progressive increase in the success rate of radiofrequency catheter ablation and decrease in the duration of successful ablation sessions cannot be attributed to technologic advances. It is probable that these gradual improvements in efficacy and efficiency resulted from a progressive increase in operator experience. The operator skills required for successful catheter ablation of accessory pathways include mapping of the accessory pathway, identification of appropriate target sites for energy delivery, and catheter manipulation. The slow and continuous improvement in success and shortening of procedure duration observed in this study suggests that the skills required to achieve a single-session success rate of $96 \%$ are learned gradually. Although the results of this study do not enable us to determine if the skills required for catheter manipulation or mapping/identification of appropriate target sites are more difficult to learn, the absence of a significant decrease in the number of applications of radiofrequency energy delivered during successful ablation sessions suggests that skills required for catheter manipulation may be the most challenging.

Two prior studies reported an improvement in the success of radiofrequency catheter ablation with increased experience in series of 75 and 99 patients. 3.4 Schluter et $\mathrm{al}^{3}$ reported that the efficacy of radiofrequency catheter ablation increased from $50 \%$ among the first 10 patients to $100 \%$ after 50 patients, whereas Leather et $\mathrm{al}^{4}$ reported an increase in the success rate from $55 \%$ among the first 20 patients to $88 \%$ among the most recent group of 33 patients. In the study by Schluter, the improvement in efficacy resulted from increases in both the size of the ablation electrode and operator experience. Furthermore, the success rate reported in both of these series reflected that of initial and subsequent attempts at catheter ablation. In contrast, in the present study, the technology used for catheter ablation was similar in all patients, the outcome of only the first attempt at catheter ablation was evaluated, and the analysis was performed in a much larger series of patients.

Jackman et al ${ }^{1}$ successfully ablated 174 of 177 accessory pathways during the initial attempt at catheter ablation. The success rate of $98 \%$ achieved by these investigators may be attributable to prior experience with catheter mapping of accessory pathways ${ }^{7}$ and to longer procedure durations (mean duration $8.3 \pm 3.5$ hours). In contrast, the duration of procedures was limited to 4 hours in this study, which may be more representative of standard clinical practice.

1. Jackman WM, Wang $X$, Friday KJ, Roman CA, Moulton KP, Beckman KJ, McClelland JH, Twidale N, Hazlitt HA, Prior MI, Margolis PD, Calame JD. Overholt ED, Lazzara R. Catheter ablation of accessory atrioventricular pathways (WolffParkinson-White syndrome) by radiofrequency current. $N$ Engl J Med 1991;324: 1605-1611.

2. Calkins H, Sousa J, El-Atassi R, Rosenheck S, de Buitleir M, Kou WH, Kadish AH, Langberg JJ, Morady F. Diagnosis and cure of the Wolff-Parkinson-White syndrome or paroxysmal supraventricular tachycardias during a single electrophysiologic test. N Engl I Med 1991;324:1612-1618.

3. Schluter M, Geiger M, Siebels J, Duckeck W, Kuck KH. Catheter ablation using radiofrequency current to cure symptomatic patients with tachyarrhythmias related to an accessory atrioventricular pathway. Circulation 1991;84:1644-1661.

4. Leather RA, Leitch JW, Klein GJ, Guiraudon GM, Yee R, Kim YH. Radiofrequency catheter ablation of accessory pathways: a learning experience. Am J Cardiol 1991;68:1651- 1655 .

5. Calkins H, Langerg J, Sousa J, El-Atassi R, Leon A, Kou W, Kalbfleisch S Radiofrequency catheter ablation of accessory atrioventricular connections in 250 patients: an abbreviated therapeutic approach to the Wolff-Parkinson-White syndrome. Circulation 1992;85:1337-1346.

6. Lesh MD, Van Hare GF, Schamp DJ, Chien W, Lee MA, Griffin JC, Langberg JJ, Cohen TJ, Lurie KG, Scheinman MM. Curative percutaneous catheter ablation using radiofrequency energy for accessory pathways in all locations: results in 100 consecutive patients. J Am Coll Cardiol 1992:19:1303-1309.

7. Jackman WM, Friday KJ, Fitzgerald DM, Bowman AJ, Yeung-Lai-Wah JA, Lazzara R. Localization of left free-wail and postcroseptal accessory atrioventricular pathways by direct recording of accessory pathway activation. PACE 1989; 12:204-213. 